\title{
Learned Helplessness and Socialization: A Reflective Analysis
}

\author{
Atasi Mohanty1, Rabindra Kumar Pradhan², Lalatendu Kesari Jena² \\ ${ }^{1}$ Centre for Educational Technology, Indian Institute of Technology Kharagpur, Kharagpur, India \\ ${ }^{2}$ Department of Humanities and Social Science, Indian Institute of Technology Kharagpur, Kharagpur, India \\ Email: atasim@cet.iitkgp.ernet.in, rkpradhan@hss.iitkgp.ernet.in, lkjena@iitkgp.ac.in,
}

Received 26 March 2015; accepted 15 June 2015; published 18 June 2015

Copyright (C) 2015 by authors and Scientific Research Publishing Inc.

This work is licensed under the Creative Commons Attribution International License (CC BY). http://creativecommons.org/licenses/by/4.0/

(c) (i) Open Access

\begin{abstract}
The growth of an individual is an area of great scientific concern. The malleability of a human being in its physiological and psychological structure makes room for external influences. A multitude of influence interacts with a professional's psychological structure and molds it in various ways. It has been understood that the pattern of socialization is a potent source of influence for growth of professional. Hence, it is important to recognize that the growth not only means the execution of certain responses, but also inhibitions of certain other responses. Therefore, we presume from such a stand point that an understanding of negative forces is as important as that of positive forces and the explanation of such negative factors is essential for harnessing the growth of a professional. This assumption is primarily drawn because as our skills and abilities surface under some stimulating condition, the competence at the same time may likely to be suppressed by some negative factors. Through this conceptual paper, we would like to bring the learned helplessness in which such negative influences of socialization are conceptualized and predicted.
\end{abstract}

\section{Keywords}

Learned Helplessness, Depression, Disease Susceptibility, Coping with Undesirable Life Events, Work Inefficiency, Socialization

\section{Introduction}

The phenomenon of learned helplessness was first proposed and studied by Seligman and Maier (1967). Originally the theory has stated that an organism develops helplessness as a reaction to situation of uncontrollability. Experimental animals exposed to inescapable situation learn that responses and outcomes are independent. Human beings who are exposed to insoluble problems for a long period of time discover that responses and events 
are un-related. Learning acquired in this situation impairs future learning and leads to passivity. Subsequently, the organism fails to solve subsequently a problem, even if there is a solution for the problem. Seligman and Maier (1967) observed that Mongreal dogs following exposure to inescapable electric shock showed striking deficits later, when placed in a shuttle box in which the simple act of crossing a barrier would terminate the shock. The phenomenon is described as learned helplessness which refers to learning or perception that responses and outcomes are independent. A number of experimental studies have indicated that this learned helplessness is a broad dimension and it operates as an induced trait (Sahoo \& Mohapatra, 1986) in such subjects. The concept of control as a core construct in the theory of learned helplessness has received much attention (Langer, 1983). In this connection, quite a good number of investigators have documented learned helplessness in human beings (Bauer et al., 2003; Bodner \& Mikulincer, 1998; Cemalcilar, Canbeyli, \& Sunar, 2003; Fosco \& Geer, 1971; Gatchel \& Proctor, 1976; Glass \& Singer, 1972; Hatfield \& Job, 1998; Palker-Corell \& Marcus, 2004).

However, Seligman's model has broadened the scope of learned helplessness from animal behaviour to a wide variety of human behaviours that include child development, disease susceptibility, old age problem and depression (Seligman, 1975). Other investigators have also argued that the learned helplessness model is useful in studying intellectual development (Dweck \& Licht, 1980), crowding (Rodin, 1976), victimization (Wortman \& Dintzer, 1978), and ageing (Schulz \& Hanusa, 1980). Like animal research, helplessness theory when applies to humans has been controversial (Peterson et al., 1982).

The laboratory studies have yielded inconsistent results, suggesting that the phenomenon in human being is more complicated than with animals. The applications have often been generally metaphorical and have sometimes regarded all instances of passive behaviour as learner helplessness (Overmier, 2002). There is a helplessness phenomenon in humans (as demonstrated in the experimental laboratory and the cognitive explanation seems to account for some of the important factors about depression (Miller \& Seligman, 1976). On the other side of the fence, the generality of the construct has engaged research attention.

The phenomenon of learned helplessness is observed across many species. The typical human helplessness experiment involves a triadic design in which one group of subjects receives controllable events; a second group of subjects receives uncontrollable events of the same intensity and duration. A third group of subjects is not expressed to either controllable or uncontrollable events. Hiroto and Seligman's (1975) experiment is a typical example of human helplessness study. The events in this study involved loud noise. Participants could terminate loud controllable noises by pressing a button four times, uncontrollable noises terminated independently of their responses. All participants subsequently were tested on a handle of shuttle box task in which noise termination was controllable. The result of this test paralleled the results of animal experiments.

The generality of the phenomenon across situation was also observed. Hiroto and Seligman (1975) conducted a series of experiments and employed both instrumental and cognitive tasks in pre-training and post-training situation of instrumental nature, learned helplessness and cognitive situations. He has found that learned experience gets developed as a reaction to uncontrollable cognitive situations and generalizes to instrumental situations. Thus, we can infer that irrespective of the domain of controllability, helplessness is indicated in instrumental and cognitive activities.

\section{Dissecting Helplessness}

Generally, the earlier model of helplessness presents an account of debilitating effects of uncontrollability. According to the model, when an individual perceives the response outcome independence, a number of deficits result. Deficits in three interrelated areas are significant: motivational, cognitive and emotional. The motivational deficits consist of retarded initiation of voluntary responses. It reduces the motivation to control the outcome. It generates expectation that responding is an exercise in futility. In cognitive deficits, the individual feels difficult to learn the responses that produce outcomes. In fact, it interferes with learning that responding controls the outcomes. Thirdly, the emotional deficits, a depressed affect are observed when the individual learns that there is no contingency between response and outcome.

However, the earlier model is primarily couched in cognitive terms. It postulates that a mere exposure to uncontrollable events is not enough; the organism must expect that outcomes are uncontrollable. In old helplessness hypothesis, researchers have encountered an important problem with respect to individual difference factor. It is not sure that all the subjects who are similarly exposed to uncontrollable noises reach a similar conclusion, 
concerning the cause of this uncontrollability. The old helplessness hypothesis does not account for these individual differences in responses to uncontrollability and neglects the differential effects of such beliefs on self-esteem.

The old hypothesis is vague about generality and chronicity of helplessness syndrome. Helpless individuals learn that certain responses and outcomes are independent. If the new situation calls for responses similar to the original learning situation, the resulting deficits may occur. Helplessness is said to be generalized when the resulting deficits are extended to highly dissimilar stimuli or responses in the new situation. But the old theory does not explain why the expectations of uncontrollability is sometimes specific and at other times global.

At the same time, the main difficulty with the original helplessness model, when applied to human helplessness in the laboratory and to natural human depression, its failure has accounted for boundary conditions. Investigations have revealed that laboratory helplessness is general (Hiroto \& Seligman, 1975) and sometimes bad events precipitate depressive reactions which are at times transient, at times long lasting and at times even not present at all (Brown \& Harris, 1978; Lloyd, 1980). These findings put a great difficulty to trace the factors that determine chronicity and generality of helplessness and depression.

The original model does not explain the self-esteem loss, frequently observed among the depressives (Beck, 1967). Why should individuals blame themselves for events over which they don't have control? (Abramson \& Sackeim, 1977). The old hypothesis of helplessness is silent about the chronicity, generality of helplessness and depression, and about the paradox of self-esteem loss following expectation of uncontrollability.

Most of the investigators who are conscious of the shortcomings of the old model suggested that additional variables are required to explain the phenomenon (Miller \& Norman, 1986; Beevers et al., 2003) and to apply it to depression (Blaney, 1977). The new variable involved individual's interpretation of bad events (e.g.: Wortman \& Brehm, 1975). In connection with this, Abramson, Seligman and Teasdale (1978) revised helplessness theory to include the individual's causal explanations of the original bad events. Other variables may also affect response to uncontrollability (Wortman \& Dintzer, 1978). But the learned helplessness reformulation proposes that particular causal explanation tend to produce helplessness and depression following bad events.

The reformulated hypothesis states that when people face uncontrollable bad events, they ask themselves, "why?" The answer to the influences, the manner in which they will react to the bad events. Abramson et al., (1978) points out three relevant explanatory or attributional dimensions: a. internal-external b. stable-unstable c. global-specific. First of all, the cause of expectation of uncontrollability may be sometimes about the person (external explanation). It may be long lasting (stable explanation) or it may be transient (unstable explanation). The cause may affect a variety of outcomes (global expectations) or may be limited just to the concerned event (specific explanations). These three attributional dimensions are relevant in resolving different inadequacies of the original helplessness model when applied to human beings.

The first inadequacy of the old helplessness hypothesis is resolved by a proposed distinction between universal helplessness and personal helplessness. Universal helplessness promotes external attribution and personal helplessness promotes internal attribution (Abramson et al., 1978). Universal helplessness is characterized by the belief that an outcome is independent of all of one's own responses as well as the responses of other people. Personal helplessness, on the other hand is the case where the individual believes that there exist responses that would contingently produce the desired outcomes, although he or she does not possess them.

The second set of the inadequacy of the old model refers to the generality and chronicity of helplessness. According to the reformulated hypothesis, the individual makes an attribution about the cause. Some attributions have global and others have specific implication and some have chronic and others often have transient implications.

Attribution theorists (Weiner et al., 1971) have further introduced the stable-unstable dimension to account for the chronicity of helplessness. Stable factors are long lasting whereas unstable factors are short lived. Abramson et al. (1978) have suggested a third attributional dimension: "global-specific". Attributing uncontrollability to a global factor implies that helplessness will occur across situations. A specific attribution, on the other hand implies that helplessness occur only in original situation.

The reformulation analysis assigns particular roles to internality, stability and globality attributional dimensions. Internality of causal beliefs affects self-esteem loss following bad events. If the individual explains the bad events by an internal factor, self-esteem loss is likely to occur; self-esteem loss is unlikely on the other hand, if he or she explains the event by an external factor. The stability of causal events affects the chronicity of helplessness and depression. If a bad event is explained by a cause that persists, depressive reaction will lead to 
persist. Depressive reaction will be short-lived when the event is explained by a transient factor. Lastly, globality of causal beliefs influences the pervasiveness of deficits following bad events; the helplessness deficit will tend to occur in a variety of situations. In case of the belief that a more specific factor is the cause the deficits will tend to be circumscribed. Therefore, we can derive an understanding that, the three specific attributional dimensions of internality, stability and globality have reasonably resolved the inadequacies of the old hypothesis pertaining to helplessness.

\section{Application Domain of Helplessness}

Human helplessness has expanded beyond the experimental laboratory. The application has been extended to classroom, psychiatric clinic, medical hospitals and nursing homes. Investigators from the areas of social science have applied the theoretical concept of uncontrollability and helplessness to such diverse phenomena such as depression and therapy, academic achievement and sex differences etc. In 1975, Martin Seligman wrote the first book on this topic to explicate the theory of learned helplessness and to suggest the potential application to human problem such as depression, development and death etc. Since then interest and research in human helplessness has grown considerably. A wide variety of areas of application brings home its link with the quality of life. Prior to explaining the role of mechanisms that mediate between helplessness and specific negative outcomes, an explanation of these specific domains of application is essential.

\subsection{Depression}

Generally motivational, cognitive, affective and self-esteem deficits are associated with depression. Contemporary theorists have suggested that depressive symptoms might be understood in terms of causal attribution (Abramson et al., 1978). Internal attributions for bad events are associated with depressive symptoms. According to learned helplessness model of depression, the core depressive cognition is the expectation that, outcome and one's responses will be independent of each other (Seligman, 1975; Maier \& Watkins, 2000).

The syndrome of depression is a complex and heterogeneous phenomenon (Depue \& Monroe, 1978; Monroe, Slavich, \& Georgiades, 2014). Therefore, the exact kind of depression the helplessness phenomenon is not clear. In fact, there may be a subclass of depression, which is consistent with symptoms, etiology and prevention of helplessness. Mostly, this depression is originated by expectation of response-outcome independence. It is characterized by passivity, negative cognitive set and depressed affect, and may be treated with the therapeutic procedure designed to treat helplessness.

According to the speculation of Seligman (1975) both non-contingent and negative events produce helplessness and depression. The intensity of depressed affect increased with the desirability of the uncontrollable outcome or with the averseness of the unavoidable outcomes. Strength of the depressed affect depends upon the strengths of desirability. Weiner (2000) has stated that failures attributed to internal factors (such as lack of ability) produce greater negative affect compared to failure attributed to external factors (i.e. task difficulty). Thus, depressed affect is more intense in personal rather than in universal helplessness.

The universal versus personal helplessness predicts that depressed individuals attributing helplessness to internal factors (i.e. personal helplessness) will show lower self-esteem compared to those making external attributions (i.e. universal helplessness). It has been suggested by subsequent researchers that individuals with low self-esteem tend to attribute negative outcomes to internal factors and positive outcomes to external factors, and the opposite is true for high self-esteem individuals.

In contrast to the vast literature on adult depression, relatively little attention has been paid to depression in children, probably because some theorists doubt the very existence of childhood depression (e.g. Lefkowitz \& Bourton, 1978; Gaffrey, Belden, \& Luby, 2011). However, Cantwell and Carlson (1979) have observed that one should look for the clinical picture of depression in children in a way analogous to the way it is looked for in adults. Recent research starting from this assumption agrees about clustering of depressive symptoms in children which can be reliably measured (Cantwell \& Carlson, 1979; Lefkowitz \& Tesiny, 1980). According to the reformulated learner helplessness hypothesis, children with depressive symptom should be inclined to make more internal, stable and global attributions for bad events than the non-depressed peers. The learned helplessness model does not make an unequivocal prediction about depression and attributions regarding good events but the research with adults (Seligman et al., 1979) suggests that external, unstable and special attributions for good events might be associated with depressive symptoms. 
From the various studies it is seen that mother's attribution style for bad events and depressive symptoms correlated with her child's corresponding attributional style and depressive symptoms. The child may learn attributional style from his/her mother. The depressed child is apt to be found in a family in which the mother is also depressed. Brown and Haris (1978) have argued that the lack of social support is important in the development of depression.

Thus, studies of depression in children parallels between children's depressive symptoms and their attribution styles. The authors also indicate the possibility of association between children's depression and mother's attributional style. However, the possibility of transmission of parent's attribution style to their children needs further investigation.

\subsection{Disease Susceptibility}

The findings of helplessness research, especially in the area of health psychology, take an added significance, when considered in the light of recent works on the relationships between an individual's helplessness and disease susceptibility. Stress is an internal stage that occurs when an individual confronts a threat to his or her physical and psychic wellbeing (Lazarus, 1966; Nielson, Kristensen, Schnohr, \& Gronbaek, 2008). The internal state can be inferred by physiological self-report and overt behavioral measurement. More recent studies indicate that events must be negative in order to strengthen the intensity of illness. Moreover, there are some assumptions that the uncontrollability and helplessness induced by certain types of negative life changes seems to be responsible for the onset of some diseases (Paykel, 1985).

Events such as the death of a close friend, a sudden financial setback and a loss in occupational position, often lead to helplessness, depression and a tendency to give up the attempt to cope with the environment (Seligman, 1981). It has been proposed that this kind of helplessness has a role in the pathogenesis of a variety of physical diseases, ranging from the common cold to cancer. Others have shown (Greene, Goldstein, \& Moss, 1972) that sudden death is abnormally frequent among men who had been depressed for a week to several months prior to death.

There is also evidence that elevated levels of adrenalin and non-adrenalin may potentiate the development of coronary disease. Because these two catecholamines are intimately related to automatic nervous system discharge, it is not surprising that stress influences their relative presence in the blood. It is also recognized that active coping with stress leads to an increased discharge of non-adrenaline, whereas adrenaline levels remain relatively unchanged during coping (Funkenstein, Kind, \& Dralattae, 1957; Weiss, Stone, \& Hanell, 1970). Other data indicate that, though adrenaline levels sometimes rise initially to response to stressful stimulation they decline as the persons' felt ability to master the disturbing stimuli increases (Frankenhauser, 1971).

Besides stressful life events, job dissatisfaction, economic frustration, excessive work and responsibility also increases the risk of coronary disease (House, 1974; Jenkins, 1971). The jobs of people at high risk generally entail a high degree of responsibility for work overload and role conflicts. Moreover, unhappiness in non-occupational areas such as marital and family relations has also raised the occurrence of coronary disease, and acute stressors, over which the individual has little control. Forexample, the sudden death of spouse, has been highly correlated with the subsequent onset of cardiac disorders in the surviving spouses (Field \& Friedrichs, 2004).

Thus, it is well established that stress plays a vital role in pathogenesis of cardiovascular disease. Recent research suggests that there is an association between the cholesterol level in the blood and stressful life events. Stress also contributes to coronary diseases through the nonspecific physical reactions to aversive stimulations. This stimulation leads to discharge of the sympathetic nervous system and related hormones such as adrenalin and non-adrenalin (Mason, 1972). These hormonal substances, collectively termed ascatecholamines, are secreted from adrenal medulla and in case of non-adrenalin, from sympathetic nerve endings. There is evidence that catecholamines may have special significance in the development of coronary diseases. Thus, the association between helplessness and disease susceptibility signifies the construct of psychological wellbeing.

\subsection{Coping with Undesirable Life Events}

People encounter many stressful events at some crucial point of life, which can have a major impact on the course and direction of their lives. These stressful events are sometimes uncontrollable and end up with a sense of powerlessness and helplessness (e.g. Bandura, 1982; Folkman \& Moskowitz, 2000). Perceived lack of self- 
control may result from experiencing various life changes and often may lead to helplessness, powerlessness or inefficacy in given situations (e.g. Abramson, Seligman, \& Teasdale, 1978; Bandura, 1981).

Many theoretical approaches have been proposed that have potential relevance for understanding reactions to undesirable life events. Klinger (1975, 1977) maintains that when an aversive life event removes or blocks a particular goal, individuals go through a process of disengagement in which their cognitions, feelings and behaviours unfold in an orderly and predictable sequence. A person initially responds to obstacles with increased vigor to achieve the goals, may subsequently become more powerful and focused. If these initial responses are unsuccessful in obtaining the incentive, the person becomes increasingly frustrated and his behaviour becomes more stereotyped, punitive and aggressive. However, few unsuccessful attempts to achieve the outcome, individuals use to abandon their pursuit. Individuals who are attempting to cope with major life crisis may become vulnerable to other life events, and subsequently face, large number of other problems.

Brehm (1966) had developed the theory of "psychological reactance" which suggested that when free behaviour would be restricted, people respond with feelings of hostility, anger and enhanced motivation to obtain the outcome. This theoretical work is inconsistent with the learned helplessness model (Seligman, 1975). This model states that after an uncontrollable outcome individual becomes passive and depressed. Dweck and Wortman (1982) speculated that helplessness effects may be arised not from the uncontrollability of an aversive stimulus, but from the way in which the stimulus has been interpreted by the subject. Shontz (1975) maintains that individuals go through a series of counter effects as they attempt to cope with an aversive outcome. As the symptoms or problems become more pressing, people realize that their existing patterns of adjustments are inadequate and experience considerable anxiety and stress. Lazarus (1966) has focused on how a person's cognitive appraisal of a stressful situation influences the emotional responses that are elicited, the coping strategies that are employed, and the ultimate success of a person's adjustment to the crisis. He maintains that individuals appraise the significance of the situation for their well-being as well as the coping responses at their disposal, for dealing with the harm, or regard it as a challenge and focus on the potential for mastery or gain. He also emphasized that in addition to overcoming the crisis, coping responses might be directed towards controlling or regulating one's emotional reaction to the situation.

\subsection{Work Inefficiency}

The association between learned helplessness and work efficiency is of great significance. It is plausible that helpless individuals develop negative cognitive set towards work. They show less initiative towards work situation and do not experience work satisfaction. According to the learned helplessness theory (Seligman, 1975), cognitive aspects of helplessness make individuals more susceptible to a negative cognitive set. These individuals are likely to expect their efforts and work outcomes as unrelated events. This negative cognitive set is usually augmented by their early socialization experiences encountered in family, neighborhood and peer groups (Seligman \& Schulman, 1986).

The probability of early socialization, inducing helplessness is greater in Indian socio-cultural context compared to western settings. The possibility of carry-over effect is also higher in Indian situations. In India there is a greater carry-over of family norms to work situations, as the family norms and experiences are of strong influence on the individual. Kanungo and Mishra (1985) in their analysis of declining work motivation in India have indicated that the influences of socialization in India produce three types of behavioral disposition that are relevant in the context of work motivation. One, such disposition is personal helplessness. Since, there is a great deal of carry-over effect from family norms to work norms in India, personal helplessness, as an end product of past socialization, is likely to affect work motivation. Personal helplessness is positively associated with noncontingent beliefs regarding the relationships between job behaviours and expected outcomes. Personal helplessness is also associated with motivational deficits, where it is negatively related to satisfaction.

As helplessness is conceptualized as an end product of socialization, it represents a general cognitive set with respect to perception of control (Langer, 1983). So it is very important to examine the relationships between this induced personality trait and work behaviour. Two Indian researchers Sahoo and Tripathy (1990) have conducted a study to examine the association between helplessness and work behaviour. They attempted to test major predictions relating to associations amongst cognitive, affective and behavioral deficits of employees' helplessness in an industrial organization. The findings of their study revealed that individuals who are personally helpless perceive the beliefs of non-contingency and hold the cognitive expectancy that behaviours and out- 
comes are independent. Similarly, people with higher personal helplessness manifest less satisfaction and express dissatisfaction with their work environments.

In another study, Sahoo (1991) evaluated helplessness in three types of settings, namely educational, financial and industrial organization. The main purpose of his study was to test the predicted patterns of relationship among five major dimensions of helplessness like personal helplessness, universal helplessness, non-contingency, satisfaction and motivational deficits. The findings suggest that in three types of organizational setting, personal helplessness is significantly related to non-contingency and motivational deficits. Personal helplessness is negatively associated with satisfaction. This implies that helpless individuals have negative cognitive set in the form of non-contingent beliefs and they show greater motivational deficits. Helpless individuals also experience less satisfaction in their workplace. Thus, the data provide evidence concerning cognitive, motivational and affective deficits of helpless individuals.

In an organizational context, learned helplessness is primarily brought by a handful of uncontrollable, stresscreating factors which includes time and performance pressures, lack of opportunity to socialize or engage in recreational activities. To promote socialization, organizations must empower employees to work to their highest potential by providing an employee-friendly culture which reduces the learned helplessness attributions (Saxena \& Shah, 2008).

From the above studies, it is clearly indicated that personal helplessness is linked with work inefficiency. As the degree of personal helplessness increases the rate of work efficiency decreases. This happens because the controllability becomes lowered.

Helplessness is found to confine people in the cell of apathy, as it not only creates a condition of immobility for the individual, but also brings various forms of collective impoverishment. The learned helplessness theory has stated that increase in negative reinforcement results into passive, helpless behavioral responses "through increased social withdrawal, reduced interest in exploration, decreased social status, increased depressive and passive-aggressive behavior" (Seligman, 1974). The relative strength of learned helplessness is dependent on the genetic characteristics and social influence of a person. Therefore, the studies pertaining to nature/ nurture problem need to be examined. In the context of socialization it is understood that learned helplessness in case of children emerges from socio-political socialization, which is predominantly influenced by family and school environment.

\section{Learned Helplessness and Socialization}

Parental attitude has been recognized as a central component of socialization process. The attitudes and values parents carry are explicitly or implicitly mediated to their children through instructions, rewards, punishments and other techniques (Whiting, 1981). Very few studies have been done to predict positive relationship between training for independence, autonomy and children's competence.

Das (1989) has examined mother's attitude in the development of learned helplessness. He had taken one hundred and twenty (120) children both from urban high schools and some rural schools. All the children were individually administered standardized test of children's helplessness questionnaire and standardized performance test. The performance test measured their "giving up" responses. On the basis of both the tests, children in each sub-groups were classified into mastery oriented (MO) and learned helplessness (LH). Then the socialization questionnaire was administered on the mothers of MO children and LH children to measure their attitudes towards different socialization emphasis. Three dimensions of socialization (attitudinal emphasis on autonomy and independence, perception of positive consequences of independence and acceptability of the helpless child) were measured. Nineteen attitudinal items were presented and parents were asked to indicate their degree of agreement on five point rating scale, ranging from complete agreement to complete disagreement.

The results indicated that with increasing levels of helplessness of the children, urban mothers reported their perception of positive consequences of independence training to a greater extent compared to the rural mothers. With increasing helplessness of children, urban mothers lowered their acceptability of helpless children, whereas rural mothers maintained same level of their acceptability of their children. But there was no significant difference on autonomy oriented attitudes of the mothers of LH and MO children.

The study of Sahoo and Sia (1990) on maternal attitudes towards child rearing practices also indicated the same result as Das's study (1999). Sia (1990) carried out his study to examine parental attitudinal role towards their children. The design of the study was similar as that of Das study but both fathers and mothers were consi- 
dered. It also included some dimensions of attitudinal emphasis.

The results indicated that parents showed greater tolerance oriented attitude towards MO group than the LH group. Contrary to expectation greater autonomy oriented attitude and acceptability were also shown by parents of LH children in comparison to parents of MO children. Parents of boys seemed to maintain relatively same level of autonomy oriented attitude even if boys showed increasing helplessness. Whereas, parents raised their autonomy attitude when girls become more and more helpless.

When fathers and mothers were compared on their attitudinal emphasis towards children it was found that mothers indicated negative attitude to a greater extent than his fathers. Fathers indicated higher autonomy oriented attitude, which remained unchanged irrespective of the child's gender. Mother's autonomy oriented attitude coincided with father's, when directed towards boys, but attitude declined when directed towards girls.

Moreover, the role of child rearing practice is more significant compared to attitudinal emphasis. Behavioral intentions of parents towards child rearing practices are the important socio-cultural antecedents for the development of helplessness. A number of anthropologists and psychologists working on culture and personality have emphasized child rearing as a factor in personality development. Even in recent years a growing body of evidence suggests to study the relationship between child rearing and adult personality.

\section{Scope for Future Research}

As indicated earlier the construct of learned helplessness appears to be the integrative one. It provides a framework to explain a wide range of behaviours. With regard to its linkage with quality of life, it explicates a number of application areas. In view of its negative association with health inducing factors such as coping and performance, a fundamental question arises "how to mitigate helplessness".

However, helplessness reducing programmes cannot be devised unless we have an adequate understanding of its developmental processes. Considering the society as a shuttle box in which helplessness is induced, sufficient attention needs to be geared towards empirical examination of the ontogenesis of helplessness. While laboratory study of Seligman and his associates provides useful information regarding the role of various situational factors, the origin of helplessness remains uninvestigated.

Helplessness may be regarded as an outcome of early socialization experiences. More specifically, the rigidity and negativism emphasized in our family systems are likely to affect the child's development of competence. A number of socio-cultural features may also play their part. In view of this possibility, it would be crucial to examine the role of socialization as it relates to the development of child's helplessness.

\section{References}

Abramson, L. Y., \& Sackeim, H. A. (1977). A Paradox in Depression: Uncontrollability and Self-Blame. Psychological Bulletin, 84, 838-851. http://dx.doi.org/10.1037/0033-2909.84.5.838

Abramson, L. Y., Seligman, M. E. P., \& Teasdale, I. (1978). Learned Helplessness in Humans: Critique and Reformation. Journal of Abnormal Psychology, 87, 49. http://dx.doi.org/10.1037/0021-843X.87.1.49

Bandura, A. (1981). Self-Referent Thought: A Developmental Analysis of Self-Efficacy. In J. H. Flavell, \& L. Ross (Eds.), Social Cognitive Development: Frontiers and Possible Futures (pp. 200-239). Cambridge: Cambridge University Press.

Bandura, A. (1982). Self-Efficacy Mechanism in Human Agency. American Psychologist, 37, 122-147. http://dx.doi.org/10.1037/0003-066X.37.2.122

Bauer, H., Pripfl, J., Lamm, C., Prainsack, C., \& Taylor, N. (2003). Functional Neuro Anatomy of Learned Helplessness. NeuroImage, 20, 927-939. http://dx.doi.org/10.1016/S1053-8119(03)00363-X

Beck, A. T. (1967). Depression: Clinical, Experimental, and Theoretical Aspects. New York: Hoeber.

Beevers, C. G., Keitner, G. I., Ryan, C. E., \& Miller, I. W. (2003). Cognitive Predictors of Symptom Return Following Depression Treatment. Journal of Abnormal Psychology, 112, 488-496. http://dx.doi.org/10.1037/0021-843X.112.3.488

Blaney, P. H. (1977). Contemporary Theories of Depression: Critique and Comparison. Journal of Abnormal Psychology, 86, 203-223. http://dx.doi.org/10.1037/0021-843X.86.3.203

Bodner, E., \& Mikulincer, M. (1998). Learned Helplessness and the Occurence of Depressive-Like and Paranoid-Like Responses: The Role of Attentional Focus. Journal of Personality and Social Psychology, 74, 1010-1023. http://dx.doi.org/10.1037/0022-3514.74.4.1010

Brehm, J. W. (1966). A Theory of Psychological Reactance. New York: Academic Press.

Brown, G. W., \& Harris, T. O. (1978). Social Origins of Depression: A Study of Psychiatric Disorder in Women. London: 
Tavistock Publications; New York: Free Press.

Cantwell, D. P., \& Carlson, G. (1979). Problems and Prospects in the Study of Childhood Depression. Journal of Nervous \& Mental Disease, 167, 522-529. http://dx.doi.org/10.1097/00005053-197909000-00002

Cemalcilar, Z., Canbeyli, R., \& Sunar, D. (2003). Learned Helplessness, Therapy, and Personality Traits: An Experimental Study. Journal of Social Psychology, 143, 65-81. http://dx.doi.org/10.1080/00224540309598431

Das, V. (1989). Voices of Children. Daedalus, 118, 263-294.

Depue, R. A., \& Monroe, S. M. (1978). Learned Helplessness in the Perspective of the Depressive Disorders: Conceptual and Definitional Issues. Journal of Abnormal Psychology, 87, 3-20. http://dx.doi.org/10.1037/0021-843X.87.1.3

Dweck, C. S., \& Licht, B. G. (1980). Learned Helplessness and Intellectual Achievement. In J. Garber, \& M. E. P. Seligman (Eds.), Human Helplessness: Theory and Application. New York: Academic Press.

Dweck, C. S., \& Wortman, C. B. (1982). Learned Helplessness, Anxiety, and Achievement Motivation: Neglected Parallels in Cognitive, Affective, and Coping Responses. In H. W. Krohne, \& L. Laux (Eds.), Achievement, Stress, and Anxiety (pp. 93-125). Washington DC: Hemisphere.

Field, N. P., \& Friedrichs, M. (2004). Continuing Bonds in Coping with the Death of a Husband. Death Studies, 28, 597-620. http://dx.doi.org/10.1080/07481180490476425

Folkman, S., \& Moskowitz, J. T. (2000). Positive Affect and the Other Side of Coping. American Psychologist, 55, 647-654. http://dx.doi.org/10.1037/0003-066X.55.6.647

Fosco, F., \& Geer, J. H. (1971). Effects of Gaining Control over Aversive Stimuli after Differing Amounts of No Control. Psychological Reports, 29, 1153-1154. http://dx.doi.org/10.2466/pr0.1971.29.3f.1153

Frankenhauser, M. (1971). Behavior and Circulating Catecholamines. Brain Research, 31, 241-262. http://dx.doi.org/10.1016/0006-8993(71)90180-6

Funkenstein, D. H., King, S. H., \& Drollette, M. E. (1957). Mastery of Stress. Cambridge, MA: Harvard University Press. http://dx.doi.org/10.4159/harvard.9780674332911

Gaffrey, M. S., Belden, A. C., \& Luby, J. L. (2011). The 2-Week Duration Criterion and Severity and Course of Early Childhood Depression: Implications for Nosology. Journal of Affective Disorders, 133, 537-545. http://dx.doi.org/10.1016/j.jad.2011.04.056

Gatchel, R., \& Proctor, J. (1976). Physiological Correlates of Learned Helplessness in Man. Journal of Abnormal Psychology, 85, 27-34. http://dx.doi.org/10.1037/0021-843X.85.1.27

Greene, W. A., Goldstein, S., \& Moss, A. J. (1972). Psychosocial Aspects of Sudden Death: A Preliminary Report. Archives of Internal Medicine, 129, 725-731. http://dx.doi.org/10.1001/archinte.1972.00320050049005

Hatfield, J., \& Job, R. F. S. (1998). Random Yoking: An Alternative to Feedback Procedures for Preventing Superstition in the Human Learned Helplessness Paradigm. Learning and Motivation, 29, 416-434.

http://dx.doi.org/10.1006/lmot.1998.1010

Hiroto, D. S., \& Seligman, M. E. P. (1975). Generality of Learned Helplessness in Man. Journal of Personality and Social Psychology, 31, 311-327. http://dx.doi.org/10.1037/h0076270

House, J. S. (1974). Occupational Stress and Coronary Heart Disease: A Review and Theoretical Integration. Journal of Health and Social Behavior, 15, 12-27. http://dx.doi.org/10.2307/2136922

Jenkins, C. D. (1971). Psychologic and Social Precursors of Coronary Disease. The New England Journal of Medicine, 284, 307-317. http://dx.doi.org/10.1056/NEJM197102112840607

Kanungo, R. N., \& Misra, S. (1985). Developing Work Motivation in India. Indian Management Journal, All Indian Management Association, 6-14.

Klinger, E. (1975). Consequences of Commitment to and Disengagement from Incentives. Psychological Review, 82, 1-25. http://dx.doi.org/10.1037/h0076171

Klinger, E. (1977). Meaning and Void: Inner Experience and the Incentives in People’s Lives. Minneapolis: University of Minnesota Press.

Langer, E. J. (1983). The Psychology of Control. London: Sage Publications.

Lazarus, R. S. (1966). Psychological Stress and the Coping Process. New York: McGraw-Hill.

Lefkowitz, M. M., \& Tesiny, E. P. (1980). Assessment of Childhood Depression. Journal of Consulting and Clinical Psychology, 48, 43-50. http://dx.doi.org/10.1037/0022-006X.48.1.43

Lefkowitz, M. M., \& Burton, N. (1978). Childhood Depression: A Critique of the Concept. Psychological Bulletin, 85, 716726. http://dx.doi.org/10.1037/0033-2909.85.4.716

Lloyd, C. (1980). Life Events and Depressive Disorder Reviewed: Events as Precipitating Factors. Archives of General Psy- 
chiatry, 37, 541-548. http://dx.doi.org/10.1001/archpsyc.1980.01780180055005

Maier, S. F., \& Watkins, L. R. (2000). Learned Helplessness. In A. E. Kazdin (Ed.), Encyclopedia of Psychology (Vol. 4, pp. 505-508). London: Oxford University Press. http://dx.doi.org/10.1037/10519-217

Mason, J. W. (1972). Organization of Psychoendocrine Mechanisms: A Review and Reconsideration of Research. In N. Greenfield, \& R. Sternbach (Eds.), Handbook of Psychophysiology (pp. 3-76). New York: Holt, Rinehart \& Winston.

Miller, I. W., \& Norman, W. H. (1986). Persistence of Depressive Cognitions within a Subgroup of Depressed Inpatients. Cognitive Therapy and Research, 10, 211-224. http://dx.doi.org/10.1007/BF01173726

Miller, W. R., \& Seligman, M. E. P. (1976). Learned Helplessness, Depression, and the Perception of Reinforcement. Behaviour Research and Therapy, 14, 7-17. http://dx.doi.org/10.1016/0005-7967(76)90039-5

Monroe, S. M., Slavich, G. M., \& Georgiades, K. (2014). The Social Environment and Depression: The Importance of Life Stress. In I. H. Gotlib, \& C. L. Hammen (Eds.), Handbook of Depression (3rd ed., pp. 296-314). New York: Guilford Press.

Nielson, N. R., Kristensen, T. S., Schnohr, P., \& Gronbaek, M. (2008). Perceived Stress and Cause Specific Mortality among Men and Women: Results from a Prospective Study. American Journal of Epidemiology, 168, 481-491. http://dx.doi.org/10.1093/aje/kwn157

Overmier, J. B. (2002). On Learned Helplessness. Integrative Physiological and Behavioral Science, 37, 4-8. http://dx.doi.org/10.1007/BF02688801

Palker-Corell, A., \& Marcus, D. K. (2004). Partner Abuse, Learned Helplessness, and Trauma Symptoms. Journal of Social and Clinical Psychology, 23, 445-462. http://dx.doi.org/10.1521/jscp.23.4.445.40311

Paykel, E. S. (1985). The Clinical Interview for Depression. Development, Reliability and Validity. Journal of Affective Disorders, 9, 85-96. http://dx.doi.org/10.1016/0165-0327(85)90014-X

Peterson, C., Semmel, A., Von Baeyer, C., Abramson, L. Y., Metalsky, G. I., \& Seligman, M. E. P. (1982). The Attributional Style Questionnaire. Cognitive Therapy and Research, 6, 287-299. http://dx.doi.org/10.1007/BF01173577

Rodin, J. C. (1976). Density, Perceived Choice, and Response to Controllable and Uncontrollable Outcomes. Journal of Experimental Social Psychology, 12, 564-578. http://dx.doi.org/10.1016/0022-1031(76)90035-4

Sahoo, F. M., \& Tripathy, S. (1990). Learned Helplessness in Industrial Employees: A Study of Non-Contingency, Satisfaction and Motivational Deficits. Psychological studies, 35, 79-87.

Sahoo, F. M. (1991). Learned Helplessness in Organizations. Management and Labour Studies, 16, 1-10.

Sahoo, F. M., \& Mohapatra, C. (1986). Helplessness Syndrome: Present Status and Future Directions. Indian Journal of Community Guidance, 3, 11-20.

Sahoo, F. M., \& Sia, N. (1990). Role of Socio-Cultural Antecedents in the Development of Helplessness. Unpublished Report, Bhubaneshwar, India: Psychology Department, Utkal University.

Saxena, S., \& Shah, H. (2008). Effect of Organizational Culture on Creating Learned Helplessness Attributions in R\&D Professionals: A Canonical Correlation Analysis. Vikalpa: The Journal for Decision Makers, 33, 25.

Schulz, R., \& Hanusa, B. (1980). Applications of Experimental Social Psychology to Aging. Journal of Social Issues, 36, 30-47. http://dx.doi.org/10.1111/j.1540-4560.1980.tb02020.x

Seligman, M. E. P. (1974). Depression and Learned Helplessness. In R. J. Friedman, \& M. M. Katz (Eds.), The Psychology of Depression: Contemporary Theory and Research (pp. 83-113). Washington DC: Winston.

Seligman, M. E. P. (1975). Helplessness: On Depression, Development and Death. San Francisco, CA: Freeman.

Seligman, M. E. P., Abramson, L. Y., Semmel, A., \& Von Baeyer, C. (1979). Depressive Attributional Style. Journal of Abnormal Psychology, 88, 242-247. http://dx.doi.org/10.1037/0021-843X.88.3.242

Seligman, M. E. P., \& Maier, S. F. (1967). Failure to Escape Traumatic Shock. Journal of Experimental Psychology, 74, 1-9. http://dx.doi.org/10.1037/h0024514

Seligman, M. E. P. (1981). A Learned Helplessness Point of View. In L. Rehm (Ed.), Behavior Therapies for Depression. New York: Academic Press.

Seligman, M. E. P., \& Schulman, P. (1986). Explanatory Style as a Predictor of Productivity and Quitting among Life Insurance Agents. Journal of Personality and Social Psychology, 50, 832-838. http://dx.doi.org/10.1037/0022-3514.50.4.832

Shontz, E. C. (1975). The Psychological Aspects of Physical Illness and Disability. New York: Macmillan.

Sia, N. (1990). Role of Socio-Cultural Antecedents in the Development of Helplessness. The Indian Journal of Social Work, 52, 325-336. 
Weiner, B. (2000). Intrapersonal and Interpersonal Theories of Motivation from an Attributional Perspective. Educational Psychology Review, 12, 1-14. http://dx.doi.org/10.1023/A:1009017532121

Weiner, B., Frieze, I., Kukla, A., Reed, L., Rest, S., \& Rosenbaum, R. M. (1971). Perceiving the Causes of Success and Failure. Morristown, NJ: General Learning Press.

Weiss, J. M., Stone, E. A., \& Hanell, N. (1970). Coping Behavior and Brain nor Epinephrine Levels in Rats. Journal of Comparative and Physiological Psychology, 72, 153-160. http://dx.doi.org/10.1037/h0029311

Whiting, J. W. M. (1981). Environmental Constraints on Infant Care Practices. In R. H. Munroe, R. L. Munroe, \& B. B. Whiting (Eds.), Handbook of Cross-cultural Human Development (pp. 155-179). Garland Press: New York.

Wortman, C. B., \& Dintzer, L. (1978). Is an Attributional Analysis of the Learned Helplessness Phenomenon Viable? A Critique of the Abramson-Seligman-Teasdale Reformulation. Journal of Abnormal Psychology, 87, 75-90. http://dx.doi.org/10.1037/0021-843X.87.1.75

Wortman, C. B., \& Brehm, J. W. (1975). Responses to Uncontrollable Outcomes: An Integration of Reactance Theory and the Learned Helplessness Model. In L. Berkowitz (Ed.), Advances in Experimental Social Psychology (Vol. 8, pp. 277336). New York: Academic Press. http://dx.doi.org/10.1016/s0065-2601(08)60253-1 